\title{
A DFT ANALYSIS OF THE MOLECULAR STRUCTURES AND VIBRATIONAL SPECTRA OF 1,3,5-TRIBROMO-2,4,6-TRIFLUORO-BENZENE
}

A.Pragasam $^{a b}$, S.Stella Mary ${ }^{b}$ and K.Sambathkumar ${ }^{c} *$

${ }^{a}$ Research scholar. St.Peter's University, Avadi. Chennai-54

${ }^{b}$ St.Peter's University, Avadi. Chennai-54

${ }^{c}$ P.G.\&Research Department of Physics,(Computational and Theoretical Divisions),A.A.Govt. Arts College, TamilNadu, India.

e-mail ID: : sa75kumar@yahoo.co.in

ABSTRACT : A combined experimental and theoretical studies were conducted on the molecular structure and vibrational, spectra of 1,3,5-tribromo-2,4,6-trifluoro-benzene(TBFB). The FT-IR and FT-Raman spectra of $(\mathrm{TBB})$ were recorded in the solid phase. The molecular geometry and vibrational frequencies of TBB in the ground state have been calculated by using density functional methods (B3LYP) invoking 6-31++G (d,p) basis set. The optimized geometric bond lengths and bond angles obtained by (B3LYP) method shows best agreement with the experimental values. Comparison of the observed fundamental vibrational frequencies of TBFB with calculated results by density functional methods indicates that B3LYP is superior. A detailed interpretation of the FT-IR, FT-Raman, NMR spectra of TBFB was also reported Natural bond orbital analysis has been carried out to explain the change transfer or delocalization of change due to the intramolecular interactions. The HOMO and LUMO energies and electronic charge transfer (ECT) confirms that local reactivity and global reactivity descriptors. High field indicates that this molecule exhibit considerable electrical conductivity in atomic charges.The ESP map is found to be positive throughout the backbone of the molecule. The negative charges have a tendency to drift from left to right. Thermodynamic parameters like heat capacities $\left(C_{p, m}^{o}\right)$, entropies $\left(S_{m}^{o}\right)$ and enthalpies changes $\left(H_{m}^{o}\right)$ are used for various electrical field.

Key words: TBFB,NMR, HOMO - LUMO, NBO, ESP.

\section{I.INTRODUCTION}

Aromatic bromo compounds or their derivatives are used as solvents, analytical reagents, and are important intermediates in organic synthesis of perfumes, drugs, pesticides, and explosives [1-4]. Aromatic nitro compounds are convertible by reduction into primary amines, which in turn are valuable intermediates in the synthesis of dyes, pharmaceuticals, photographic developers and antioxidants [5]. The organic hydrocarbons having one or more $\mathrm{Br}$ groups bonded to the carbon framework, are versatile intermediate in organic synthesis. The bromo ion in hydrogen compounds is trigonally planar with $120^{\circ}$ angles. There are two resonance bonds so that the three $\mathrm{F}$ are equivalent. Bromo compounds are strongly basic due to electron withdrawing both inductively and mesomerically. Historically, they are abundant in dyes and explosives. 1,3,5-tribromo-2,4,6-trifluoro-benzene are used as an intermediate for organic compounds; pharmaceuticals, pesticides and dyes. Both the compounds are pale yellow in colour and insoluble in water. It is harmful by inhalation, in contact with skin and if swallowed, and it also irritates to eyes, respiratory system and skin. 1,3,5-tribromo-2,4,6-trifluoro-benzene is useful as an intermediate in the preparation. Haloaromatic compounds are well known building blocks in the synthesis of pharmaceuticals and agrochemicals. Traditionally, the halogen has normally been chlorine but bromo aromatics are assuming greater importance as the cost-effectiveness of biologically active fluorine containing products and the synthesis value of $\mathrm{C}$ substituents becomes more widely acknowledged [6-8]. The photoelectron spectra of tribromo-trifluoro-benzene studied only the conventional infrared and Raman spectra with normal coordinate analysis. The complete FT-IR and FT-Raman vibrational studies on the fundamental modes and the electronic property investigations by NMR spectrum, NBO analysis, FMO's and thermodynamic properties are not found in the literature. The resulting demand of bromo aromatics has led to search for commercially attractive, flexible and to investigate the entire properties of TBFB. Thus, a detailed investigation have been attempted using B3LYP/6-311G++(d,p) basis sets to provide more satisfactory and valuable informations on electronic stability, molecular orbitals, potential energy distribution and NMR spectral characteristics of TBB. The atomic charges, distribution of electron density (ED) in various bonding and antibonding orbitals and stabilisation energies, $\mathrm{E}^{(2)}$ have been calculated by natural bond orbital (NBO) analysis. The optimised geometry, frontier molecular orbital (FMO) and their energy gaps, molecular electrostatic potential map (MESP), total density region and electrostatic potential contour (ESP) map have been constructed at B3LYP/6-311G++(d,p) level to understand the electronic properties, electrophilic and nucleophilic active centers of TBB. The temperature dependence of the thermodynamic functions and their 
correlations were performed at B3LYP/6-311G++(d,p).

\section{EXPERIMENTAL WORK}

The pure compound 1,3,5-tribromo-2,4,6-trifluoro-benzene was purchased from Lancaster chemical company U.K., and used as such without any further purification. The room temperature fourier transform infrared (FTIR) spectrum of the title molecule was recorded in the region $4000-400 \mathrm{~cm}^{-1}$ at a resolution of $\pm 1 \mathrm{~cm}^{-1}$ using a BRUKER IFS 66V FTIR spectrophotometer equipped with a cooled MCT detector. Boxcar apodization was used for the 250 averaged interferograms collected for both the samples and background. The FT-Raman spectrum was recorded on a computer interfaced BRUKER IFS model interferometer, equipped with FRA 106 FT-Raman accessory in the $3500-50 \mathrm{~cm}^{-1}$ stokes region, using the $1064 \mathrm{~nm}$ line of Nd:YAG laser for excitation operating at $200 \mathrm{~mW}$ power. The reported wave numbers are believed to be accurate within $\pm 1 \mathrm{~cm}^{-1}$.

\section{III.COMPUTATIONAL METHODS}

DFT-B3LYP is adopted using 6-311G++(d,p) as basis set to give complete information concerning the structural characteristics and the fundamental vibrational modes of the title compounds. The calculations of geometrical parameters in the ground state are performed using GAUSSIAN 09W [9] program. The first hyperpolarizability, HOMO-LUMO and ESP analyses under various electric fields, NBO analysis are carried out by B3LYP/6$311 \mathrm{G}++(\mathrm{d}, \mathrm{p})$ method. The thermodynamic functions such as entropy, enthalpy and the heat capacity are investigated for the different temperatures. Molecular structure is specified in Fig 1. But the geometrical parameters such as bond lengths, bond angles are the important factors in
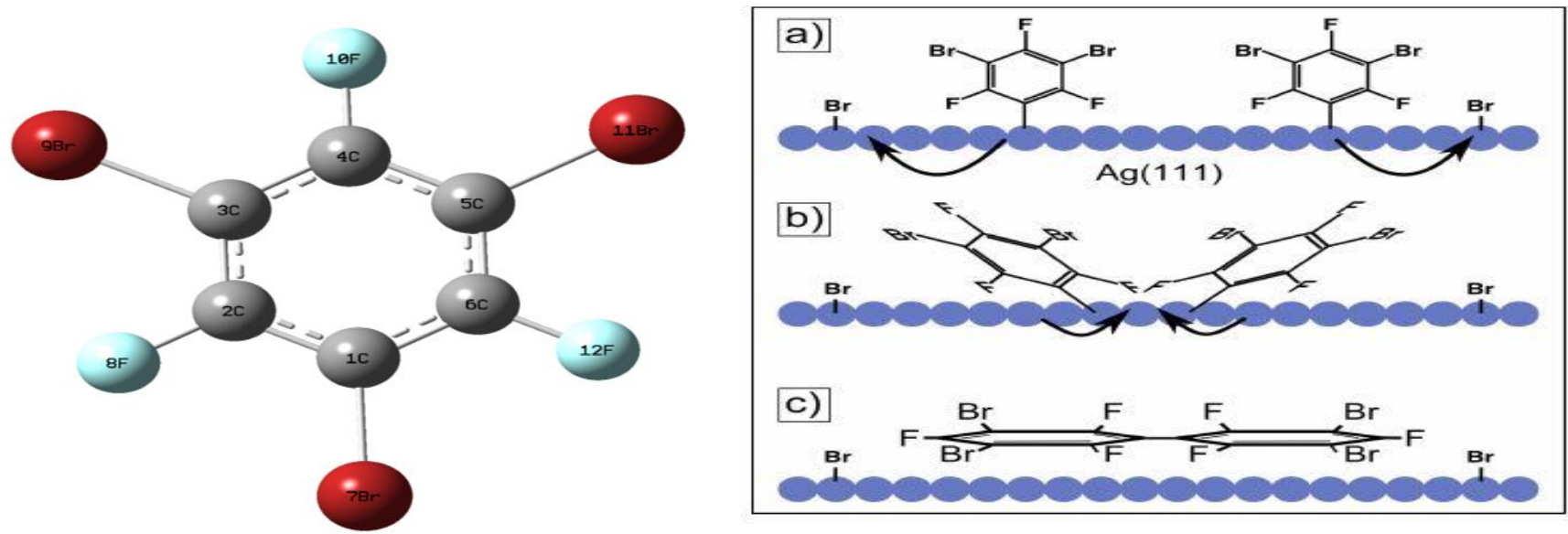

Fig.1: Molecular structure of 1,3,5-tribromo-2,4,6-trifluoro-benzene. Fig 2 Schematic view of the reaction pathway from 1,3,5-tribromo-2,4,6trifluoro-benzene monomers to dimers.

Table 1

Optimized parameters of 1,3,5-tribromo-2,4,6-trifluoro-benzene using B3LYP/6-311++G(d,p) method

\begin{tabular}{|c|c|c|c|c|c|c|c|c|}
\hline \multirow{2}{*}{$\begin{array}{l}\text { Bond } \\
\text { Length }\end{array}$} & \multicolumn{2}{|c|}{ Values $(\AA)$} & \multirow{2}{*}{$\begin{array}{c}\text { Bond } \\
\text { Angle } \\
\end{array}$} & \multicolumn{2}{|c|}{ Values $\left({ }^{\circ}\right)$} & \multirow{2}{*}{$\begin{array}{c}\text { Dihedral } \\
\text { Angle }\end{array}$} & \multicolumn{2}{|c|}{ Values $\left(^{\circ}\right)$} \\
\hline & Monomer & Dimer & & Monomer & Dimer & & Monomer & Dimer \\
\hline $\mathrm{C} 1-\mathrm{C} 2$ & 1.3923 & $\begin{array}{l}1.3951 / \\
1.3955 \\
\end{array}$ & C2-C1-C6 & 114.4352 & $\begin{array}{l}123.56 / \\
123.57 \\
\end{array}$ & C6-C1-C2-C3 & 0.2032 & $\begin{array}{l}179.90 / \\
179.99 \\
\end{array}$ \\
\hline C1-C6 & 1.0822 & $\begin{array}{l}1.0839 / \\
1.0839 \\
\end{array}$ & C2-C1-Br12 & 120.4471 & $\begin{array}{l}119.31 / \\
119.32 \\
\end{array}$ & C6-C1-C2-F7 & -179.7731 & $\begin{array}{l}-179.78 / \\
-179.79 \\
\end{array}$ \\
\hline C1-C34 & 1.3941 & $\begin{array}{l}1.3990 / \\
1.3991\end{array}$ & C6-F8-Br12 & 111.9368 & $\begin{array}{l}128.19 / \\
128.20\end{array}$ & $\mathrm{Br} 12-\mathrm{C} 1-\mathrm{C} 2-\mathrm{C} 3$ & -0.0959 & $\begin{array}{l}0.0813 / \\
0.0824\end{array}$ \\
\hline $\mathrm{C} 2-\mathrm{C} 3$ & 1.0838 & $\begin{array}{l}1.098 / \\
1.0982\end{array}$ & $\mathrm{C} 1-\mathrm{C} 2-\mathrm{C} 3$ & 130.1204 & $\begin{array}{l}117.11 / \\
117.12\end{array}$ & Br12-C1-C2-F7 & 179.8702 & $\begin{array}{l}179.99 / \\
180.99\end{array}$ \\
\hline C2-F7 & 1.3859 & $\begin{array}{l}1.3720 / \\
1.3721 \\
\end{array}$ & C1-C2-F7 & 117.9138 & $\begin{array}{l}126.13 / \\
126.14 \\
\end{array}$ & C2-C1-C6-C5 & 179.9817 & $\begin{array}{l}-0.099 / \\
-0.099 \\
\end{array}$ \\
\hline C3-C4 & 1.088 & $\begin{array}{l}1.0943 / \\
1.0944 \\
\end{array}$ & C3-C2-F7 & 115.1853 & $\begin{array}{l}115.22 / \\
115.23 \\
\end{array}$ & C2-C1-C6-Br10 & -0.0521 & $\begin{array}{l}179.98 / \\
179.99 \\
\end{array}$ \\
\hline C3-Br10 & 1.3632 & $\begin{array}{l}1.4799 / \\
1.4799\end{array}$ & $\mathrm{C} 2-\mathrm{C} 3-\mathrm{C} 4$ & 132.7684 & $\begin{array}{l}135.22 / \\
135.71 \\
\end{array}$ & Br10-C1-C6-C5 & 0.0651 & $\begin{array}{c}179.99 / \\
179.99\end{array}$ \\
\hline $\mathrm{C} 4-\mathrm{C} 5$ & 1.0843 & $\begin{array}{l}1.3920 / \\
1.3921\end{array}$ & C2-C3-Br10 & 112.9745 & $\begin{array}{l}114.21 / \\
114.22\end{array}$ & Br11-C1-C6-F9 & 179.9847 & $\begin{array}{l}0.0097 / \\
0.0098\end{array}$ \\
\hline C4-F8 & 1.3882 & $\begin{array}{l}1.4523 / \\
1.4554 \\
\end{array}$ & C4-C3-Br10 & 114.0209 & $\begin{array}{l}116.13 / \\
116.14 \\
\end{array}$ & C2-C1-Br12-F8 & 179.7903 & $\begin{array}{l}-0.0253 / \\
-0.0264\end{array}$ \\
\hline
\end{tabular}




\begin{tabular}{|c|c|c|c|c|c|c|c|c|}
\hline C5-C6 & 1.411 & $\begin{array}{l}1.3955 / \\
1.3958\end{array}$ & $\mathrm{C} 3-\mathrm{C} 4-\mathrm{C} 5$ & 123.5507 & $\begin{array}{c}124.86 / 124 \\
.89\end{array}$ & C6-C1-Br11-F8 & 0.0093 & $\begin{array}{l}180.95 \\
181.99\end{array}$ \\
\hline C5-F9 & 1.3865 & $\begin{array}{l}1.4278 / \\
1.4288\end{array}$ & C3-C4-F8 & 122.4276 & $\begin{array}{l}121.67 / \\
121.68\end{array}$ & C1-C2-C3-C4 & -0.02112 & $\begin{array}{l}179.9 \\
179.9\end{array}$ \\
\hline Br10-H11 & 1.4157 & $\begin{array}{l}1.0883 / \\
1.0893\end{array}$ & C5-C4-F8 & 117.1557 & $\begin{array}{l}113.32 / 113 \\
.33\end{array}$ & C1-C2-C3-Br10 & 179.9753 & $\begin{aligned}-0.06 \\
-0.069\end{aligned}$ \\
\hline Br10-F7 & 1.0783 & $\begin{array}{l}1.4236 / \\
1.4246\end{array}$ & C4-C5-C6 & 127.7998 & $\begin{array}{l}132.16 / \\
132.17\end{array}$ & F7-C2-C3-C4 & 178.9574 & $\begin{array}{r}0.502 \\
0.5025\end{array}$ \\
\hline Br12-F9 & 1.4116 & $\begin{array}{l}1.4882 / \\
1.4892\end{array}$ & C4-C5-F9 & 115.0424 & $\begin{array}{l}118.88 / 118 \\
.89\end{array}$ & F7-C2-C3-Br10 & -0.0472 & $\begin{array}{r}-0.52 \\
-0.525 \\
\end{array}$ \\
\hline Br12-F8 & 1.4582 & $\begin{array}{l}1.3933 / \\
1.3933 \\
\end{array}$ & C6-C5-F9 & 125.041 & $\begin{array}{c}117.54 / 117 \\
.55\end{array}$ & $\mathrm{C} 2-\mathrm{C} 3-\mathrm{C} 4-\mathrm{C} 5$ & 0.0841 & $\begin{array}{r}0.08 \\
0.089\end{array}$ \\
\hline \multicolumn{9}{|c|}{$\begin{array}{l}\text { Table } 2 \\
\text { Definition of internal coordinates of 1,3,5-tribromo-2,4,6-trifluoro-benzene. }\end{array}$} \\
\hline No. (i) & Symbol & Type & \multicolumn{6}{|c|}{ Definition } \\
\hline $1-3$ & $\mathrm{R}$ & $\mathrm{CBr}$ & \multicolumn{6}{|c|}{$\mathrm{C} 3-\mathrm{Br} 9, \mathrm{C} 1-\mathrm{Br} 7, \mathrm{C} 5-\mathrm{Br} 11$} \\
\hline $4-6$ & $\mathrm{Z}$ & $\mathrm{CF}$ & \multicolumn{6}{|c|}{ C2-F8, C4-F10,C6-F12 } \\
\hline $7-12$ & $\mathrm{X}$ & $\mathrm{CC}$ & \multicolumn{6}{|c|}{$\mathrm{C} 1-\mathrm{C} 2, \mathrm{C} 2-\mathrm{C} 3, \mathrm{C} 3-\mathrm{C} 4, \mathrm{C} 4-\mathrm{C} 5, \mathrm{C} 5-\mathrm{C} 6, \mathrm{C} 6-\mathrm{C} 1$} \\
\hline $13-18$ & Ring & $\beta$ & \multicolumn{6}{|c|}{ C1-C2-C3,C2-C3-C4,C3-C4-C5,C4-C5-C6,C5-C6-C1,C6-C1-C2 } \\
\hline $19-24$ & $\mathrm{CBr}$ & $v$ & \multicolumn{6}{|c|}{ Br7-C1-C2, Br7-C1-C6, Br9-C3-C4, Br9-C3-C2, Br11-C5-C6, Br11-C5-C4 } \\
\hline $24-30$ & $\mathrm{CF}$ & $\omega$ & \multicolumn{6}{|c|}{\begin{tabular}{|l|l|} 
F8-C2-C1,F8-C2-C3,F10-C4-C5,F10-C4-C3,F12-C6-C1,F12-C6-C5 \\
\end{tabular}} \\
\hline $31-36$ & Ring & $\tau$ & \multicolumn{6}{|c|}{$\mathrm{C} 1-\mathrm{C} 2-\mathrm{C} 3-\mathrm{C} 4, \mathrm{C} 2-\mathrm{C} 3-\mathrm{C} 4-\mathrm{C} 5, \mathrm{C} 3-\mathrm{C} 4-\mathrm{C} 5-\mathrm{C} 6, \mathrm{C} 4-\mathrm{C} 5-\mathrm{C} 6-\mathrm{C} 1, \mathrm{C} 5-\mathrm{C} 6-\mathrm{C} 1-\mathrm{C} 2, \mathrm{C} 6-\mathrm{C} 1-\mathrm{C} 2-\mathrm{C}$} \\
\hline $37-39$ & $\mathrm{CBr}$ & $\varphi$ & \multicolumn{6}{|c|}{ Br7-C1-C2-C6, Br9-C3-C2-C4, Br11-C5-C6-C4 } \\
\hline $40-42$ & $\mathrm{CF}$ & $\Delta$ & \multicolumn{6}{|c|}{ F8-C2-C3-C1, F10-C4-C5-C3, F12-C6-C5-C1 } \\
\hline
\end{tabular}

${ }^{a}$ For numbering of atoms refer Fig.1

Table 3

Definition of local symmetry coordinates of 1,3,5-tribromo-2,4,6-trifluoro-benzene.

\begin{tabular}{|c|c|c|}
\hline No. (1) & Type & Definition \\
\hline $1-3$ & CBr & $\mathrm{R}_{1}, \mathrm{R}_{2}, \mathrm{R}_{3}$ \\
\hline $4-6$ & CF & $\mathrm{Z}_{4}, \mathrm{Z}_{5}, \mathrm{Z}_{6}$ \\
\hline $7-12$ & CC & $\mathrm{X}_{7}, \mathrm{X}_{8}, \mathrm{X}_{9}, \mathrm{X}_{10}, \mathrm{X}_{11}, \mathrm{X}_{12}$ \\
\hline 13 & Rtrigd & $\left(\beta_{13}-\beta_{14}+\beta_{15}-\beta_{16}+\beta_{17}-\beta_{18}\right) / \sqrt{6}$ \\
\hline 14 & Rsymd & $\left(-\beta_{13}-\beta_{14}+2 \beta_{15}-\beta_{16}-\beta_{17}+2 \beta_{18}\right) / \sqrt{2}$ \\
\hline 15 & Rasymd & $\left(\beta_{13}-\beta_{14}+\beta_{16}-\beta_{17}\right) / \sqrt{12}$ \\
\hline $16-18$ & bCBr & $\left(v_{19}-v_{20}\right) / \sqrt{2},\left(v_{21}-v_{22}\right) / \sqrt{2},\left(v_{23}-v_{24}\right) / \sqrt{2}$ \\
\hline $19-21$ & bCF & $\left(\omega_{25}-\omega_{26}\right) / \sqrt{2},\left(\omega_{27}-\omega_{28}\right) / \sqrt{2},\left(\omega_{29}-\omega_{30}\right) / \sqrt{2}$ \\
\hline 22 & $\mathrm{t}_{1}$ Rigd & $\left(\tau_{31}-\tau_{32}+\tau_{33}-\tau_{34}+\tau_{35}-\tau_{36}\right) / \sqrt{6}$ \\
\hline 23 & $\mathrm{t}_{1}$ symd & $\left(\tau_{21}-\tau_{33}+\tau_{35}-\tau_{36} / \sqrt{2}\right.$ \\
\hline 24 & $\mathrm{t}_{1}$ asymd & $\left(-\tau_{31}+2 \tau_{32}-\tau_{33}-\tau_{34}+2 \tau_{35}-\tau_{36}\right) / \sqrt{12}$ \\
\hline $25-27$ & CBr & $\varphi_{37}, \varphi_{38}, \varphi_{39}$, \\
\hline $28-30$ & CF & $\Delta_{40}, \Delta_{41}, \Delta_{42}$ \\
\hline
\end{tabular}

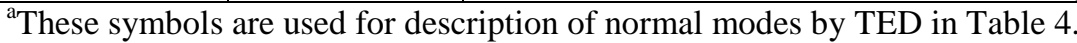

determining the electronic properties of the molecules that are listed in Table 1. This study explains the internal coordinates for TBFB (Table 2). The non-redundant set of local symmetry coordinates are constructed by linear combinations of internal coordinates using Table 3 for TBFB.

\section{IV.RESULTS AND DISCUSSIONS}

\section{IV.1. Molecular geometry}

The molecular structure of TBFB belongs to $\mathrm{C}_{1}$ point group symmetry. The molecule consists of 12 atoms and expected to have 30 normal modes of vibrations of the same a species under $\mathrm{C}_{1}$ symmetry. These modes are found to be IR and Raman active suggesting that the molecule possesses a non-centrosymmetric structure, which recommends the TBFB for non-linear optical applications. Schematic view of the reaction pathway from 1,3,5tribromo-2,4,6-trifluoro-benzene monomers to dimmers structure is specified in Fig 2.

\section{IV.2. Vibrational assignments}

The spectral analysis of title compounds is done by DFT/B3LYP method using the basis set $6-311 \mathrm{G}++(\mathrm{d}, \mathrm{p})$. The FT-IR and FT-Raman spectra of the title compounds are figured out in Figs.3, and 4 respectively and the theoretical and experimental fundamental modes of vibrations of TBFB are presented in Table 4, respectively. 

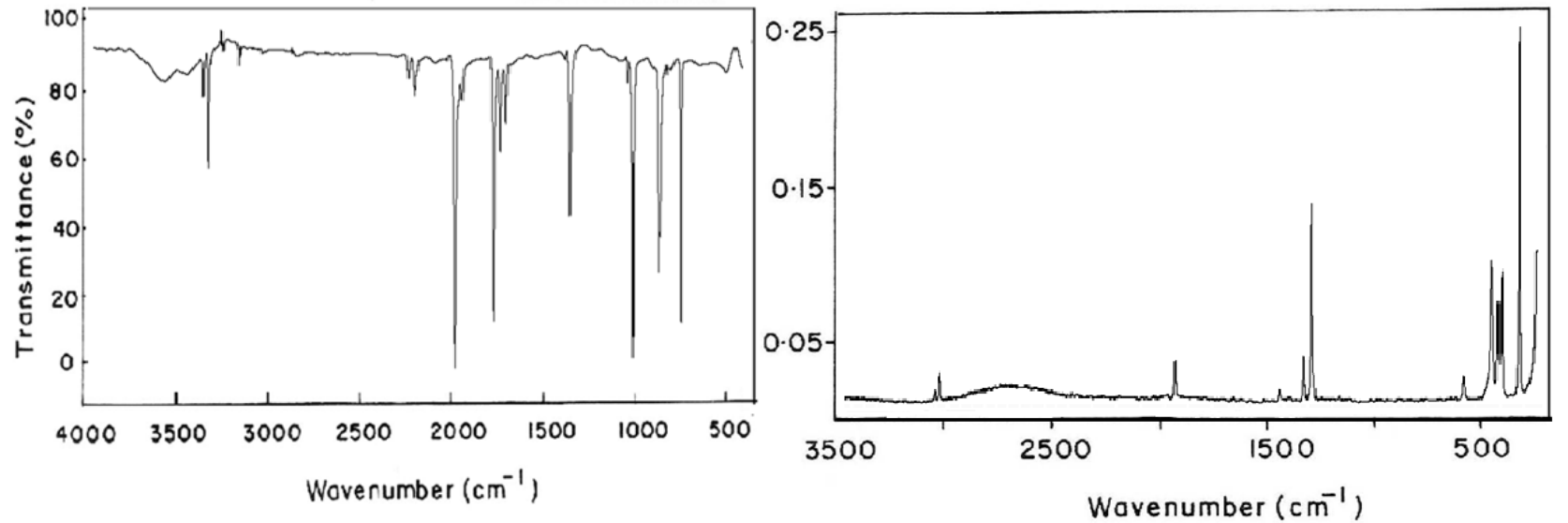

Fig.3:Experimental FTIR spectra of 1,3,5-tribromo-2,4,6-trifluoro-benzene. Fig.4: Experimental FT-Raman spectra of 1,3,5tribromo-2,4,6-trifluoro-benzene .

Table 4:

The observed (FT-IR and FT-Raman) frequencies $\left(\mathrm{cm}^{-1}\right)$ for various applied electric fields $\left(\mathrm{V} \AA^{-1}\right)$ and probable assignments (characterized by TED) of 1,3,5-tribromo-2,4,6-trifluoro-benzene using B3LYP methods.

\begin{tabular}{|c|c|c|c|c|c|c|c|}
\hline \multirow{3}{*}{$\begin{array}{l}\text { Symmetry } \\
\text { Species } \\
\mathrm{C}_{\mathrm{s}}\end{array}$} & \multicolumn{2}{|c|}{$\begin{array}{l}\text { Observed } \\
\text { frequencies } \\
\left(\mathrm{cm}^{-1}\right)\end{array}$} & \multicolumn{5}{|c|}{$\begin{array}{c}\text { Assignments with } \\
\text { TED (\%) among types of internal co-ordinates }\end{array}$} \\
\hline & \multirow{2}{*}{ FT-IR } & \multirow{2}{*}{$\begin{array}{c}\text { FT- } \\
\text { Raman }\end{array}$} & \multicolumn{2}{|c|}{$0.01 \mathrm{~V}^{-1}$} & \multicolumn{2}{|c|}{$0.02 \mathrm{~V}^{-1}$} & \\
\hline & & & + +Field & -Field & +Field & -Field & \\
\hline A & $3099 w$ & - & 3358 & 3196 & 3656 & 3356 & $v \mathrm{CH}(99)$ \\
\hline A & $3056 \mathrm{w}$ & $3057 w$ & 3357 & 3184 & 3615 & 3351 & $v \mathrm{CH}(97)$ \\
\hline A & $2075 w$ & - & 3346 & 3181 & 3290 & 3244 & vCHC (96) \\
\hline A & $1805 \mathrm{w}$ & - & 3342 & 3172 & 3267 & 3231 & $v \mathrm{CC}(94)$ \\
\hline $\mathrm{A}$ & $1776 \mathrm{w}$ & - & 3338 & 3166 & 3142 & 3125 & $v \mathrm{C} \mathrm{C}(92)$ \\
\hline A & $1763 w$ & - & 3331 & 3151 & 3107 & 3100 & $v C C(89)$ \\
\hline A & $1758 w$ & - & 1632 & 1617 & 1711 & 1701 & $v C C(87)$ \\
\hline $\mathrm{A}$ & $1741 \mathrm{~s}$ & - & 1591 & 1553 & 1620 & 1605 & $v \mathrm{CC}(78), v \mathrm{CH}(20)$ \\
\hline A & $1623 \mathrm{~s}$ & - & 1553 & 1518 & 1561 & 1545 & $v \mathrm{CC}(72), v \mathrm{CH}(24)$ \\
\hline $\mathrm{A}$ & $1472 w$ & - & 1527 & 1509 & 1490 & 1456 & $\mathrm{bCH}(71), v \mathrm{CH}(21)$ \\
\hline A & $1424 w$ & - & 1475 & 1461 & 1450 & 1423 & $\mathrm{bCH}(70), v \mathrm{CH}(20)$ \\
\hline $\mathrm{A}$ & $1411 \mathrm{w}$ & - & 1425 & 1415 & 1417 & 1401 & $\mathrm{bCH}(75), v \mathrm{CH}(14)$ \\
\hline $\mathrm{A}$ & $870 \mathrm{w}$ & - & 1394 & 1382 & 1329 & 1319 & Rtrigd (73), $v \mathrm{CH}(22)$ \\
\hline A & $860 w$ & - & 1348 & 1332 & 1279 & 1255 & Rsymd $(69, \mathrm{bC}=\mathrm{O}(26)$ \\
\hline A & $842 \mathrm{~s}$ & - & 1340 & 1312 & 1248 & 1232 & Rasym (68),bCH(30) \\
\hline $\mathrm{A}$ & $645 w$ & - & 1291 & 1287 & 1205 & 1195 & $\omega \mathrm{CH}(65), \mathrm{bCH}(29)$ \\
\hline A & $632 w$ & - & 1266 & 1256 & 1170 & 1152 & $\omega \mathrm{CH}(66), \mathrm{bCH}(28)$ \\
\hline $\mathrm{A}$ & $612 \mathrm{w}$ & - & 1206 & 1200 & 1118 & 1103 & $\omega \mathrm{CH}(64), \mathrm{bCH}(27)$ \\
\hline $\mathrm{A}$ & $528 \mathrm{~s}$ & - & 1141 & 1132 & 1075 & 1056 & $v \mathrm{CBr}(63), \mathrm{R}_{1} \operatorname{asym}(27)$ \\
\hline A & $512 w$ & - & 1123 & 1114 & 1069 & 1031 & $v \mathrm{CBr}(60), \mathrm{R}_{1} \operatorname{symd}(31)$ \\
\hline A & $502 \mathrm{w}$ & - & 1052 & 1041 & 1020 & 1007 & $v \mathrm{CBr}(62), \mathrm{R}_{1} \operatorname{trigd}(34)$, \\
\hline $\mathrm{A}$ & $478 w$ & $479 w$ & 1009 & 1000 & 969 & 954 & $\mathrm{bCBr}(67), \mathrm{R}_{2} \operatorname{asym}(30)$ \\
\hline A & - & $456 \mathrm{w}$ & 998 & 988 & 947 & 931 & $\mathrm{bCBr}(68), \mathrm{R}_{2} \operatorname{symd}(21)$ \\
\hline A & $432 w$ & - & 995 & 976 & 909 & 897 & $\mathrm{bCBr}(60), \mathrm{R}_{2} \operatorname{trigd}(38)$ \\
\hline $\mathrm{A}$ & $411 \mathrm{w}$ & - & 947 & 931 & 906 & 863 & tRtrigd(57), $\omega \mathrm{CH}(7)$ \\
\hline$\overline{\mathrm{A}}$ & - & $403 w$ & 929 & 913 & 841 & 825 & tRsymd(51), $\omega \mathrm{CH}(9)$ \\
\hline A & $389 w$ & - & 889 & 857 & 769 & 754 & tRasym(52) \\
\hline A & $126 \mathrm{~s}$ & - & 831 & 821 & 731 & 722 & $\omega \mathrm{CBr}(51) \mathrm{tR}_{1} \operatorname{asym}(47)$ \\
\hline A & $103 \mathrm{vs}$ & - & 811 & 801 & 660 & 643 & $\omega \mathrm{CBr}(50) \mathrm{tR}_{1} \operatorname{symd}(50)$ \\
\hline A & $99 \mathrm{~s}$ & - & 774 & 753 & 644 & 622 & $\omega \mathrm{CBr}(55) \mathrm{tR}_{1} \operatorname{trigd}(34)$ \\
\hline
\end{tabular}

Abbreviations: $\quad v$-stretching; ss - symmetric stretching; ass - asymmetric stretching; $b$ - bending; $\omega$ - out-of-plane bending; $R$ ring; trigd - trigonal deformation; symd - symmetric deformation; asymd - antisymmetric deformation; $t$ - torsion; $s$ - strong; 
vs - very strong; ms - medium strong; $w$-weak; vw-very weak.

\section{Carbon vibrations}

The aromatic ring carbon-carbon stretching modes are expected in the range from 1650 to $1200 \mathrm{~cm}-1$. The observed peaks of TBFB are 1805,1776,1763,1758,1741,1623 cm-1 are recognized as the C-C stretching modes, respectively [10,11]. All the bands lie in the expected range when compared to the literature values. These observed frequencies show that, the substitutions in the ring to some extend affect the ring mode of vibrations. The comparison of the theoretically (Positive field and negative field) values are good agreement with B3LYP/6$311++\mathrm{G}(\mathrm{d}, \mathrm{p})$ method. The in-plane and out-of-plane bending vibrations of $\mathrm{C}-\mathrm{C}$ group are also listed out in the Table 4 for TBFB.

\section{C-Br Vibrations}

The vibrations that are belonging to the bond between the ring and the halogen atoms are worth to discuss here, since mixing of vibrations are possible due to the presence of heavy atoms on the periphery of the compound [11]. C-X bond show lower absorption frequencies as compared to $\mathrm{C}-\mathrm{H}$ bond due to the decreased negative field and increase in positive field. Further, $\mathrm{Br}$ causes redistribution of charges in the ring. Bromine compounds absorbed in the region $650-485 \mathrm{~cm}^{-1}$ due to the $\mathrm{C}-\mathrm{Br}$ stretching vibrations. In $\mathrm{C}-\mathrm{Br}$ stretching vibrations are observed at 528,512,502 $\mathrm{cm}^{-1}$ in the IR spectrum for TBFB, and for IR and Raman spectrum $684 \mathrm{~cm}^{-1}$ and 670,631 $\mathrm{cm}^{-1}$ are assigned for TBB. The observed C-Br in-plane-bending and C-Br out-of-plane bending modes show consistent agreement with Positive field and negative field.

\section{C-F vibrations}

In the vibrational spectra of $\mathrm{TBB}$, the bands due to the $\mathrm{C}-\mathrm{F}$ stretching vibrations may be found over a wide frequency range $1360-1000 \mathrm{~cm}^{-1}$ [11], since the vibration is easily affected by adjacent atoms (or) groups. In the present investigation, the FTIR and FT-Raman bands observed at 1299, 1283, $1270 \mathrm{~cm}^{-1}$ and $1298,1282 \mathrm{~cm}^{-1}$ have been assigned to $\mathrm{C}-\mathrm{F}$ stretching modes of vibrations. The $\mathrm{C}-\mathrm{F}$ in-plane and out-of-plane bending vibrations are observed at $1259,1237,1204 \mathrm{~cm}^{-1}$ in IR and 212, 169,145 $\mathrm{cm}^{-1}$ in Raman, respectively. Theoretical Positive field and negative field showed excellent agreement with recorded spectrum.

\section{HOMO-LUMO ENERGY GAP AND RELATED MOLECULAR PROPERTIES}

The analysis of the wave function is mainly described by one-electron excitation from the highest occupied molecular orbital (HOMO) to the lowest unoccupied molecular orbital. The HOMO-LUMO analysis of these two compounds is done at B3LYP/6- 311++G(d,p) level of theory for the zero field and fields of $0.05,0.15$ and 0.25 $V^{-1}$. Fig. 5 illustrates the orbital distributions of HOMO and LUMO levels of the title compounds for the zero field and biasing steps of $0.05,0.15$ and $0.25 \mathrm{VA}^{-1}$. HOMO is delocalized mainly on ring carbons; the Fluorine of bromine also takes part in the formation of HOMO of TBFB for zero field. The strong electron withdrawing group $\mathrm{HBr}$ of phenyl ring attracts the charge density while on other hand electron donating group bromine is attached on left hand of TBFB which would strengthen the donor ability. Hence LUMOs are distributed on the phenyl ring. In TBFB, HOMO is delocalized mainly on ring carbons and there is no distribution of HOMO on bromine of phenyl ring [12]. The values of HOMO energy, LUMO energy and HOMO-LUMO energy gap are used as an indicator of kinetic stability of the molecule. They are nearly same which shows that substituted bromine and Fluorine would have no effect on the title compounds. When the field increases $\left(0.0-0.20 \mathrm{VA}^{-1}\right)$, the HOMO-LUMO gap (HLG) extensively decreases from $0.0409 \mathrm{eV}$ to $0.1789 \mathrm{eV}$ for of 1,3,5-tribromo-2,4,6-trifluoro-benzene, respectively (as shown in Table 5). This large decrease in the HLG implies that the possibility of having reasonable conduction through the molecule, hence the conductivity increases with decreases in HLG.

Table: 5 Electronic Properties with various Electric Field's of 1,3,5-tribromo-2,4,6-trifluoro-benzene.

\begin{tabular}{|c|c|c|c|c|}
\hline Parameters & $0.00 \mathrm{VA}^{-1}$ & $0.05 \mathrm{VA}^{-1}$ & $0.1 \mathrm{VA} \AA^{-1}$ & $0.2 \mathrm{VA}^{-1}$ \\
\hline HOMO(a.u) & -0.2370 & -0.2819 & -0.2099 & -0.2824 \\
\hline LUMO( a.u) & -0.1961 & -0.1097 & -0.1654 & -0.1035 \\
\hline Energy Gap (Eg) (a.u) & 0.0409 & 0.1722 & 0.0445 & 0.1789 \\
\hline Chemical Hardness( $\eta$ ) (a.u) & 0.08512 & 0.06512 & 0.0472 & 0.09451 \\
\hline Chemical Potential $(\mu)(a . u)$ & -0.20390 & -0.20407 & -0.29701 & -0.28660 \\
\hline Electronegativity $(\chi)$ (a.u) & +0.23910 & +0.22571 & +0.29704 & +0.28065 \\
\hline Softness $(\mathrm{S})(\mathrm{a} . \mathrm{u})$ & 12.58921 & 12.80360 & 30.33411 & 21.78031 \\
\hline Electrophilicity Index ( $\omega)$ (a.u) & 0.7908 & 0.39653 & 0.92312 & 0.77267 \\
\hline
\end{tabular}




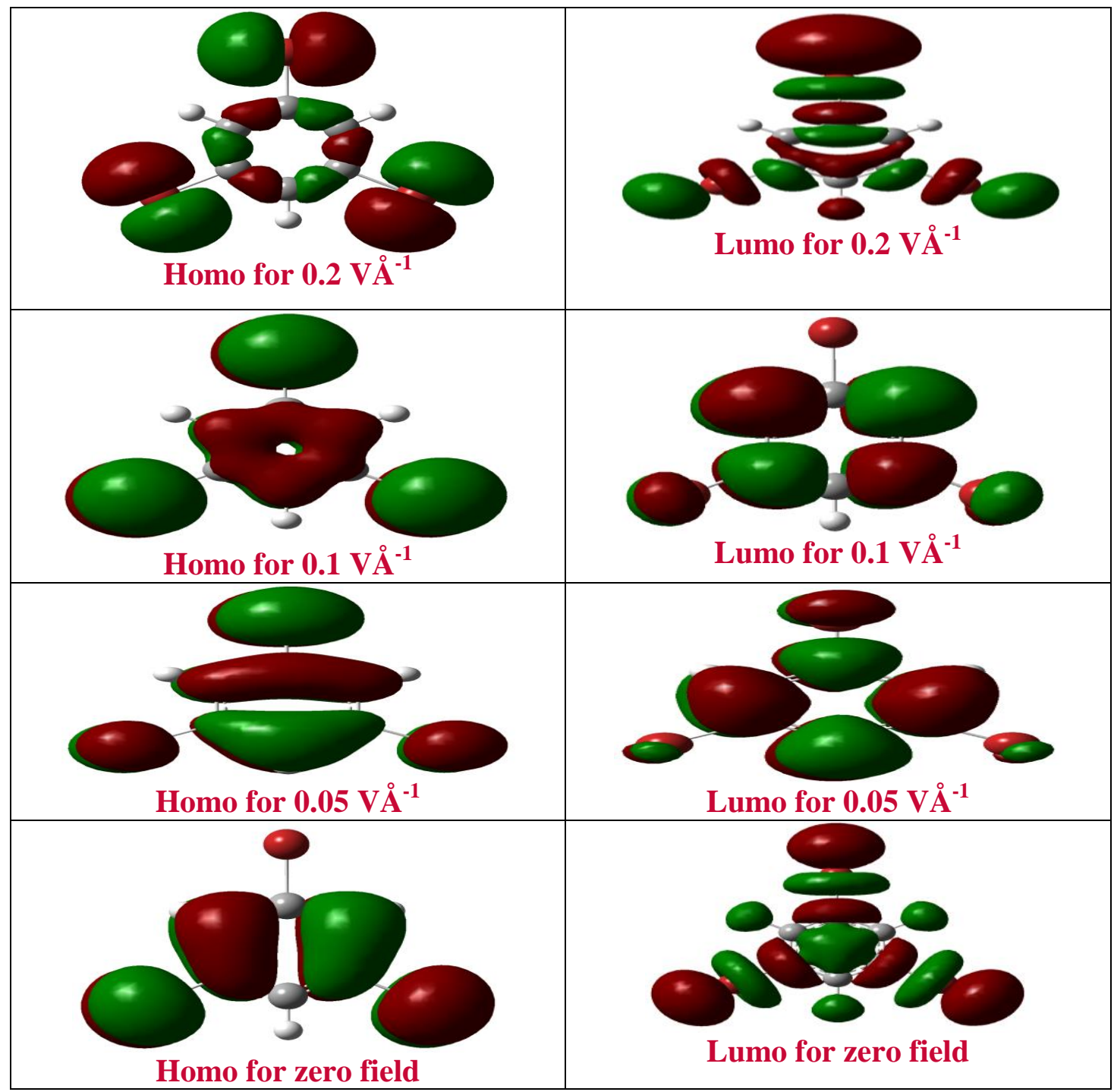

Fig 5: Isosurface representation of molecular orbitals of 1,3,5-tribromo-2,4,6-trifluoro-benzene.

\section{NBO ANALYSIS}

NBO analysis gives information about interactions in both filled and virtual orbital spaces that could enhance the analysis of intra- and intermolecular interactions. The larger the $\mathrm{E}^{(2)}$ (energy of hyperconjugative interactions) value, the more intensive is the interaction between electron donors and electron acceptors, i.e. the more donating tendency from electron donors to electron acceptors the greater the extent of conjugation of the whole system. Delocalization of electron density between occupied Lewis-type (bond or lone pair) NBO orbitals and formally unoccupied (anti-bond or Rydberg) non-Lewis NBO orbitals correspond to a stabilizing donor-acceptor interaction. NBO analysis has been performed on the title molecule at the DFT level in order to elucidate the intramolecular, re-hybridization and delocalization of electron density within the molecule. These interactions can reveal the electron transfer (hyperconjugative effect) between the orbital localized in these atoms. NBO analysis is carried out for the most stable form of the title compounds by DFT/B3LYP method using the basis set 6$311 \mathrm{G}++(\mathrm{d}, \mathrm{p})$. The interaction energies between donor and acceptor orbital for both compounds are shown in Table 6 , respectively. By analyzing these data, an effective energy interaction between the lone pair $\operatorname{LP}(2) \operatorname{Br} 9 \pi-$ antibonding orbitals of $(\mathrm{C} 1-\mathrm{Br} 7)$ bond is observed in the compound. This implies that an electron transport from nitrogen LP to antibonding orbital (hyperconjugative effect) [13]. The electron donation from the $\operatorname{LP}(2) \operatorname{Br} 11$, $\mathrm{LP}(1) \mathrm{F} 10$ to the anitbonding acceptor $\pi^{*} \mathrm{C} 3-\mathrm{C} 4, \pi^{*} \mathrm{Br} 9-\mathrm{C} 3$ is observed which leads to moderate stabilization energy in the compound as shown in Table 6. 
Table 6

Selected second order perturbation energies $\mathrm{E}^{(2)}$ associated with $\mathrm{i}->\mathrm{j}$ delocalization in gas phase.

\begin{tabular}{|c|c|c|c|c|c|c|}
\hline \multicolumn{7}{|c|}{ 1,3,5-tribromo-2,4,6-trifluoro-benzene } \\
\hline Donor(i) & Type & Acceptor (j) & Type & $\mathrm{E}^{(2) \mathrm{a}}\left(\mathrm{kJ} \mathrm{mol}^{-1)}\right.$ & $\varepsilon_{(\mathrm{j})}-\varepsilon_{(\mathrm{i})}{ }^{\mathrm{b}}$ (a.u.) & $\mathrm{F}(\mathrm{I}, \mathrm{j})^{\mathrm{c}}$ (a.u.) \\
\hline \multirow[t]{3}{*}{$\mathrm{C} 1-\mathrm{C} 2$} & $\pi$ & $\mathrm{C} 3-\mathrm{C} 4$ & $\pi^{*}$ & 9.65 & 0.29 & 0.067 \\
\hline & & $\mathrm{C} 5-\mathrm{C} 6$ & $\pi^{*}$ & 9.64 & 0.30 & 0.068 \\
\hline & & $\mathrm{C} 11-\mathrm{Br} 12$ & $\pi^{*}$ & 12.71 & 1.26 & 0.074 \\
\hline \multirow[t]{2}{*}{$\mathrm{C} 3-\mathrm{C} 4$} & $\pi$ & $\mathrm{C} 1-\mathrm{C} 2$ & $\pi^{*}$ & 11.11 & 0.27 & 0.070 \\
\hline & & $\mathrm{C} 5-\mathrm{C} 6$ & $\pi^{*}$ & 9.88 & 0.28 & 0.067 \\
\hline \multirow[t]{2}{*}{ C5 - C6 } & $\pi$ & $\mathrm{C} 1-\mathrm{C} 2$ & $\pi^{*}$ & 11.11 & 0.27 & 0.070 \\
\hline & & $\mathrm{C} 3-\mathrm{C} 4$ & $\pi^{*}$ & 10.34 & 0.27 & 0.068 \\
\hline \multirow[t]{2}{*}{$\mathrm{LP}(2) \mathrm{Br} 9$} & $\mathrm{n}_{2}$ & $\mathrm{C} 1-\mathrm{Br} 7$ & $\sigma^{*}$ & 10.62 & 0.27 & 0.068 \\
\hline & & Br7- F8 & $\sigma^{*}$ & 20.22 & 0.28 & 0.068 \\
\hline LP(1)F10 & $\mathrm{n}_{1}$ & $\mathrm{Br} 9-\mathrm{C} 3$ & $\pi^{*}$ & 9.33 & 0.29 & 0.066 \\
\hline $\mathrm{LP}(2) \mathrm{Br} 11$ & $\mathrm{n}_{1}$ & $\mathrm{C} 3-\mathrm{C} 4$ & $\pi^{*}$ & 9.81 & 0.29 & 0.068 \\
\hline
\end{tabular}

${ }^{a} \mathrm{E}(2)$ means energy of hyperconjugative interactions

${ }^{\mathrm{b}}$ The energy difference between donor and acceptor $\mathrm{i}$ and $\mathrm{j}$ NBO orbitals

${ }^{c} \mathrm{~F}(\mathrm{i}, \mathrm{j})$ is the Fock matrix element between $\mathrm{i}$ and $\mathrm{j}$ NBO orbitals.

\section{ELECTROSTATIC POTENTIALS}

Analysis of electrostatic potential (ESP) derived from the deformation electron densities on the molecular surfaces was performed to highlight the effect of crystalline environment and also to point out the differences and the similarities between the two polymorphic forms. The construction of a three-dimensional ESP map plotted over the molecular surfaces from experimental charge densities clearly brings out the differences of electrostatic nature of the three forms (Fig.6-8). The electropositive and electronegative surfaces are well separated in the forms. It displays a larger electronegative surface in ESP mapping. This is due to the conformational difference at the $\mathrm{C}-\mathrm{Br}$ side chain and additionally due to the involvement of the $\pi$ electrons of three bonded atoms C1-C2-F8 in $\mathrm{C}-\mathrm{F} \ldots \pi$ type of contacts and the presence of $\pi \ldots \pi$ contacts. The electronegative surface is mainly seen around the $\mathrm{Br}$ atoms, which are involved in $\mathrm{C}-\mathrm{H}$... Br type of intermolecular contacts. However, the atom $\mathrm{Br} 9$ shown to have less prominent electronegative surface compared to other $\mathrm{C}$ atom in the structures. This is because the atom $\mathrm{Br} 11$ is not involved in any intermolecular contacts, whereas the corresponding atom in the $\mathrm{C}$ is seen to interact remotely with the neighbour molecule. The corresponding maps from the theoretical analysis revealed similar features. The ESP maps clearly emphasize the preferred binding sites to form the networks of interactions and also highlight the difference in nature of interactions $[13,14]$.
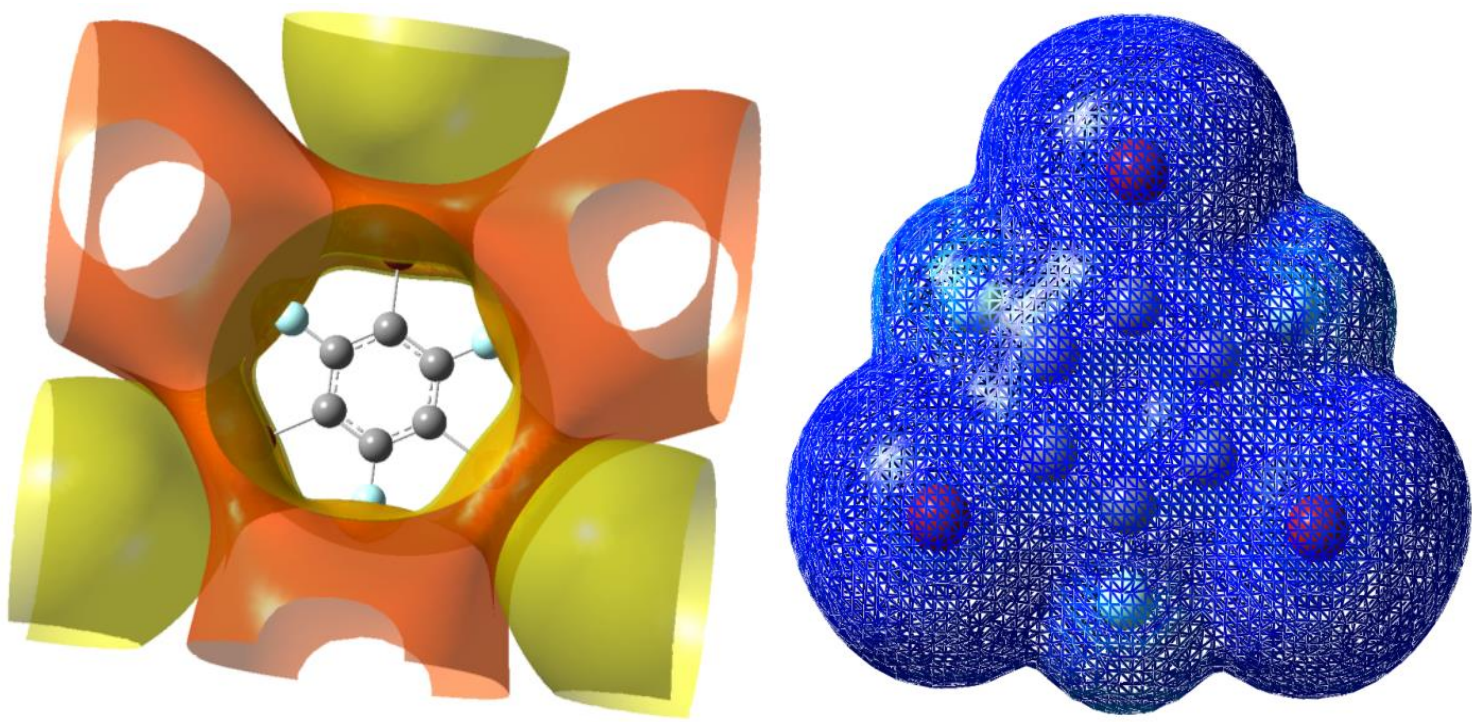

Fig.6:The total electron density surface of TBFB Fig.7:The contour map of electrostatic potential surface TBFB 


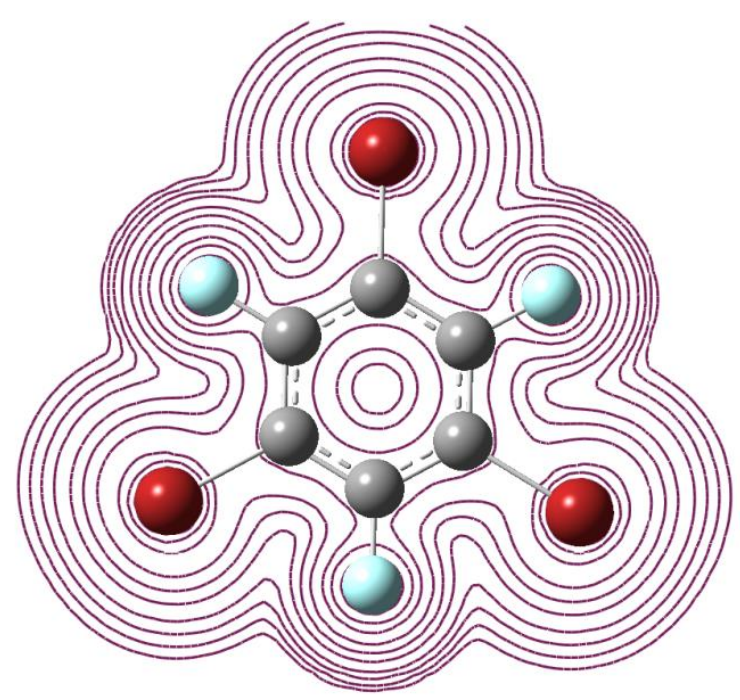

Fig.8:The molecular electrostatic potential surface of TBFB.

\section{THERMODYNAMIC PROPERTIES}

Based on the vibrational analysis at B3LYP/6-311++G(d,p) level and statistical thermodynamics, the standard thermodynamic functions; heat capacities $\left(\mathrm{C}_{\mathrm{p}, \mathrm{m}}^{\mathbf{o}}\right)$, entropies $\left(\mathrm{S}_{\mathrm{m}}^{\mathbf{o}}\right)$ and enthalpies changes $\left(\mathrm{H}_{\mathrm{m}}^{\mathrm{o}}\right)$ are obtained at constant pressure for zero (monomer and dimer) and applied electric field in Table 7. As seen from Table 7, the standard thermodynamic functions increase with increasing temperature, due to the intensities of molecular vibration increase; it is observed that the entropy increases but the enthalpy and heat capacity remain constant. According to Boyle's law for gases, a molecule is compressed at constant temperature its volume decreases [15]. Due to decreasing volume, the number of possible sites that occupied by particles of the molecule may be restricted. Thus, the entropy tends to decrease with increasing pressure at constant temperature. This investigation will be helpful for the further studies of the title molecule. The correlation graph for zero (monomer) applied EFs are shown in Fig. 9 and the corresponding fitting equations are as follows:

For $0.00 \mathrm{~V}^{-1}$

$$
\begin{gathered}
\mathrm{S}_{\mathrm{m}}^{0}=214.29646+0.72423 \mathrm{~T}-0.005228 \times 10^{-5} \mathrm{~T}^{2}\left(\mathrm{R}^{2}=0.99884\right) \\
\mathrm{C}_{\mathrm{p}, \mathrm{m}}^{0}=9.64986+0.47984 \mathrm{~T}+8.33835 \times 10^{-5} \mathrm{~T}^{2}\left(\mathrm{R}^{2}=0.99886\right) \\
\mathrm{H}_{\mathrm{m}}^{0}=-8.1464+1.13344 \mathrm{~T}-4.22106 \times 10^{-5} \mathrm{~T}^{2}\left(\mathrm{R}^{2}=0.9994\right)
\end{gathered}
$$

For $0.01 \mathrm{~V} \AA^{-1}$

$$
\begin{aligned}
& \mathrm{S}_{\mathrm{m}}^{0}=292.34312+0.13644 \mathrm{~T}+2.48899 \times 10^{-5} \mathrm{~T}^{2}\left(\mathrm{R}^{2}=0.99906\right) \\
& \mathrm{C}_{\mathrm{p}, \mathrm{m}}^{0}=1.17011+-6.47614 \mathrm{~T}-0.70196 \times 10^{-4} \mathrm{~T}^{2}\left(\mathrm{R}^{2}=0.99988\right) \\
& \mathrm{H}_{\mathrm{m}}^{0}=8.03066+4.11334 \mathrm{~T}+8.09263 \times 10^{-4} \mathrm{~T}^{2}\left(\mathrm{R}^{2}=0.99942\right)
\end{aligned}
$$

For $0.02 \mathrm{~V}^{-1}$

$$
\begin{gathered}
\mathrm{S}_{\mathrm{m}}^{0}=222.23913+0.38251 \mathrm{~T}+5.77561 \times 10^{-5} \mathrm{~T}^{2}\left(\mathrm{R}^{2}=99928\right) \\
\mathrm{C}_{\mathrm{p}, \mathrm{m}}^{0}=1.63101+0.5049 \mathrm{~T}-2.7151 \times 10^{-4} \mathrm{~T}^{2}\left(\mathrm{R}^{2}=0.9988\right) \\
\mathrm{H}_{\mathrm{m}}^{0}=-8.30066-3.1641 \mathrm{~T}+8.60392 \times 10^{-4} \mathrm{~T}^{2}\left(\mathrm{R}^{2}=0.99947\right)
\end{gathered}
$$




\section{$\mathrm{EF}: 0.00 \mathrm{~V} \AA^{-1}$}

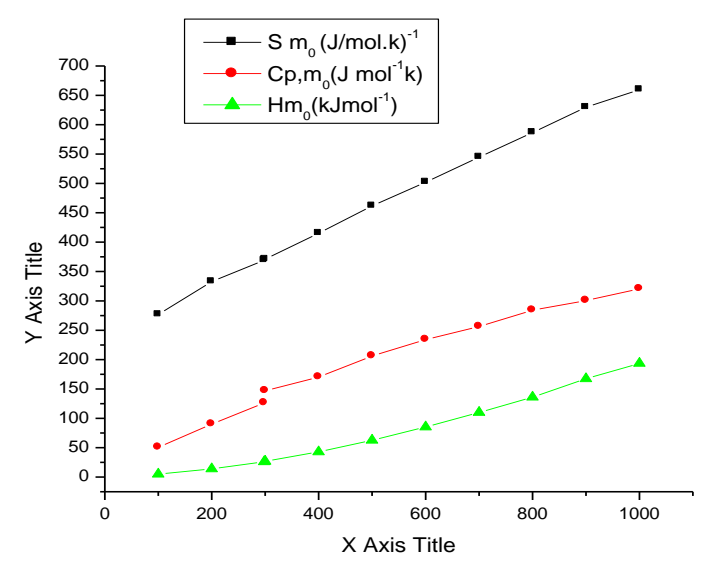

EF:0.01VÁ $\AA^{-1}$

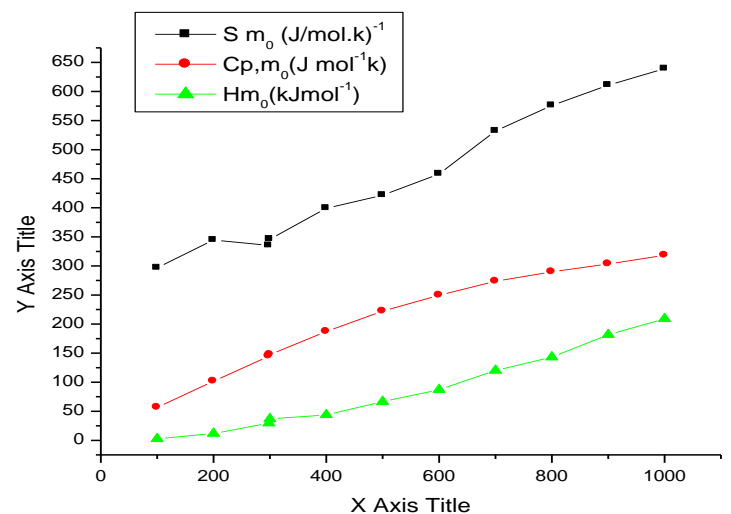

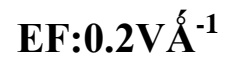

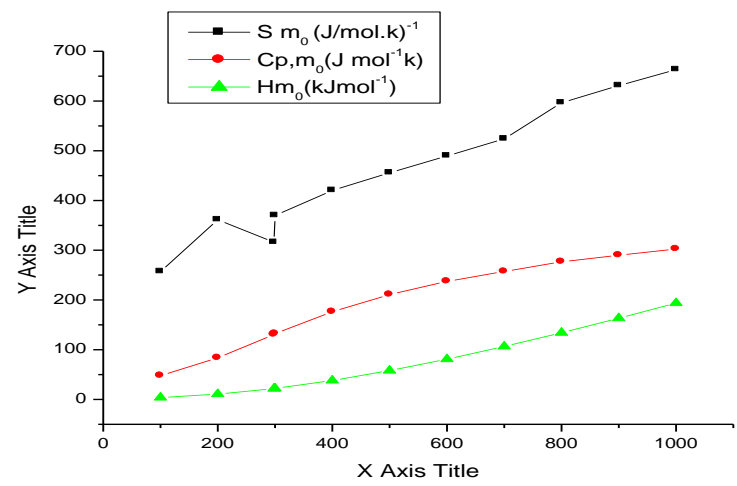

Fig. 9: Correlation graphic of thermodynamic parameters and Temperature for entropy (S), heat capacity at constant pressure (Cp), Gibb's free energy $(\mathrm{G})$ energy change of 1,3,5-tribromo-2,4,6-trifluoro-benzene.

Table 7

Thermodynamic properties at different temperatures at the B3LYP/6-311++G(d,p) level for 1,3,5-tribromo-2,4,6trifluoro-benzene.

\begin{tabular}{|c|c|c|c|c|c|c|c|c|c|c|c|c|}
\hline \multirow[b]{2}{*}{$\mathrm{T}(\mathrm{K})$} & \multicolumn{4}{|c|}{$\mathrm{S}_{\mathrm{m}}{ }^{0}(\mathrm{~J} / \mathrm{mol} . \mathrm{k})^{-1}$} & \multicolumn{4}{|c|}{$\mathrm{C}_{\mathrm{p}, \mathrm{m}}{ }^{0}\left(\mathrm{~J} \mathrm{~mol}^{-1} \mathrm{k}\right)$} & \multicolumn{4}{|c|}{$\mathrm{H}_{\mathrm{m}}^{0}\left(\mathrm{kJmol}^{-1}\right)$} \\
\hline & $\begin{array}{c}0.00 \\
\mathrm{~V}^{-1}\end{array}$ & $\begin{array}{c}0.1 \\
\mathrm{~V}^{-1}\end{array}$ & $\begin{array}{c}0.2 \\
\mathrm{~V}^{-1}\end{array}$ & Dimer & $\begin{array}{c}0.00 \\
\mathrm{~V}^{-1}\end{array}$ & $0.1 \mathrm{VA}^{-1}$ & $\begin{array}{c}0.2 \\
\mathrm{~V}^{-1}\end{array}$ & Dimer & $\begin{array}{c}0.00 \\
\mathrm{~V}^{-1}\end{array}$ & $0.1 \mathrm{VA}^{-1}$ & $0.2 \mathrm{VA}^{-1}$ & Dimer \\
\hline 100.00 & 276.76 & 296.90 & 257.12 & 491.15 & 50.50 & 56.71 & 47.83 & 180.29 & 4.98 & 2.70 & 3.92 & 9.91 \\
\hline 200.00 & 332.99 & 344.76 & 361.45 & 531.76 & 90.18 & 101.72 & 83.70 & 209.91 & 13.88 & 11.83 & 10.83 & 3.72 \\
\hline 298.15 & 369.12 & 335.23 & 316.00 & 629.09 & 126.12 & 144.73 & 130.66 & 269.57 & 25.91 & 29.64 & 21.93 & 49.81 \\
\hline 300.00 & 371.00 & 345.99 & 369.84 & 665.34 & 146.98 & 147.49 & 132.39 & 287.96 & 26.77 & 36.89 & 22.18 & 56.31 \\
\hline 400.00 & 415.23 & 399.12 & 420.34 & 751.89 & 170.33 & 187.15 & 176.25 & 361.65 & 42.90 & 43.90 & 38.10 & 91.30 \\
\hline 500.00 & 461.78 & 421.65 & 455.56 & 829.44 & 206.02 & 222.20 & 210.90 & 433.09 & 62.58 & 66.61 & 57.98 & 135.13 \\
\hline 600.00 & 502.18 & 458.22 & 489.54 & 891.40 & 234.15 & 249.59 & 237.43 & 479.36 & 85.12 & 87.23 & 81.05 & 170.74 \\
\hline 700.00 & 544.67 & 532.13 & 523.90 & 989.48 & 256.30 & 273.72 & 257.21 & 530.80 & 109.92 & 120.26 & 106.62 & 239.07 \\
\hline 800.00 & 586.61 & 575.90 & 596.66 & 1090.12 & 284.04 & 289.94 & 276.75 & 561.49 & 136.03 & 143.08 & 134.16 & 280.24 \\
\hline 900.00 & 629.72 & 610.98 & 630.98 & 1199.17 & 300.51 & 303.27 & 289.96 & 586.24 & 167.44 & 181.72 & 163.31 & 346.57 \\
\hline 1000.00 & 659.55 & 639.12 & 663.07 & 1230.80 & 320.54 & 318.40 & 302.45 & 630.40 & 193.51 & 209.00 & 193.79 & 390.53 \\
\hline
\end{tabular}

\section{ATOMIC CHARGES}

Atomic charges for molecule can be derived in multiple ways with a high level of convergence to the same values and only then, knowing the remaining uncertainty, are suited for molecular simulations.Mulliken charges arise from the mulliken population analysis [16] and provide a means of estimating partial atomic charges 
from calculations carried out by the methods of computational chemistry. Generally, Mulliken population analysis

(MPA) and Natural Population analysis (NPA) methods are used to calculate the atomic charges of atoms in molecules. The difference of MPA charges distribution for zero and various applied EFs $\left( \pm 0.2 \mathrm{~V}^{-1}\right)$ are listed in Table 8.The MPA charges of all C-atoms for zero fields vary from 4.249874a.u to -0.152586a.u for TBFB. When the applied field increases, the charge value decreases for $\mathrm{C}$-atoms. The variations in MPA charge are small due to Table 8: be systematic and almost uniform.

Mulliken’s Charges for the Zero, Various applied electric field $\left( \pm 0.2 \mathrm{~V}^{-1}\right)$ of 1,3,5-tribromo-2,4,6-trifluoro-benzene.

\begin{tabular}{|c|c|c|c|r|c|}
\hline \multirow{2}{*}{ Atom No } & \multirow{2}{*}{$0.00 \mathrm{~V}^{-1}$} & \multicolumn{2}{|c|}{$0.1 \mathrm{~V}^{-1}$} & \multicolumn{2}{c|}{$0.2 \mathrm{~V}^{-1}$} \\
\cline { 3 - 6 } & & Positive Field & Negative Field & Positive Field & Negative Field \\
\hline C1 & 0.278484 & 0.255205 & -0.233532 & 0.278428 & 0.2734201 \\
\hline C2 & -0.182081 & -2.238260 & -0.152586 & -0.231057 & -2.258607 \\
\hline C3 & 0.030104 & 2.903870 & -0.211828 & -0.187129 & 2.708055 \\
\hline C4 & -0.187183 & 4.214149 & 0.074314 & 0.030032 & 4.249874 \\
\hline C5 & -0.231086 & -1.777919 & -0.613279 & -0.182266 & -1.559169 \\
\hline C6 & 0.237985 & -1.014226 & 0.965750 & 0.358496 & -1.409223 \\
\hline F7 & -0.208201 & 0.217976 & -0.162622 & -0.182946 & 0.476902 \\
\hline F8 & -0.183020 & -0.802286 & -0.186479 & -0.217097 & -0.988622 \\
\hline F9 & 0.238916 & -0.737294 & -0.173324 & -0.171773 & -0.632975 \\
\hline Br10 & 0.250390 & -2.165958 & -0.145666 & -0.208166 & -2.986558 \\
\hline Br11 & -0.217134 & -0.423496 & -0.431863 & -0.688840 & -0.53963 \\
\hline Br12 & -0.171823 & 0.281603 & 0.236630 & 0.250341 & 0.780341 \\
\hline
\end{tabular}

\section{NMR STUDIES}

The ${ }^{13} \mathrm{C}$ theoretical and experimental chemical shifts and the assignments of the title molecule are presented in Table 9. The observed ${ }^{13} \mathrm{C}$ NMR spectra of the title molecule are given in Fig. 10. Electronegative group can increase the electron cloud density of hydrogen, and then increases chemical shift. So, the chemical shift of $\mathrm{C} 1$ atom observed at $167.473 \mathrm{ppm}$ is calculated at $110.009 \mathrm{ppm}$ for B3LYP/6-311++G(d,p) levels, respectively. Due to the deshielding effect of electronegative $\mathrm{Br} 7$ atom, the chemical shift value of $\mathrm{C} 2$ is also shifted to the downfield NMR signals -39.8453and -152.158ppm, respectively. Aromatic carbons give signals with chemical shift values in the range 100-200 ppm. All of the aromatic protons are responsible for the peaks at the range of 158.93-114.20 ppm in observed NMR spectrum. The Br proton peak is calculated at downfield region of $-39.8453 \mathrm{and} 127.53 \mathrm{ppm}$ for B3LYP/6-311++G(d,p) levels, respectively. This Experimental peak is observed at 8.141ppm in FT-NMR. From Table 9, there is general correlation between the experimental and theoretical NMR chemical shift calculations, that is, theoretical values can replace the experimental ones for the title molecule.

Table 9

The calculated shifts of carbon and hydrogen atoms of 1,3,5-tribromobenzene using B3LYP/6-311++G(d,p) GIAO method

\begin{tabular}{|c|c|c|c|}
\hline \multirow{2}{*}{ Atom position } & Theoretical & Expt $^{\mathbf{a}}$ & \multicolumn{1}{|c|}{$\boldsymbol{\Delta}$} \\
\cline { 2 - 4 } & $6-311++\mathrm{G}(\mathrm{d}, \mathrm{p}$ & & \\
\hline $\mathrm{C} 1$ & 110.009 & 167.473 & 57.464 \\
\hline $\mathrm{C} 2$ & -152.158 & & \\
\hline $\mathrm{C} 3$ & 122.033 & 129.56 & 7.527 \\
\hline $\mathrm{C} 4$ & 61.7285 & 124.456 & 62.7275 \\
\hline C5 & 132.043 & 104.56 & -27.483 \\
\hline C6 & 66.798 & 128.734 & 61.9 \\
\hline Br7 & -39.8453 & & \\
\hline Br9 & 22.357 & 66.430 & 44.073 \\
\hline Br11 & 127.53 & 135.671 & 8.141 \\
\hline F8 & 14.11 & 34.67 & 20.56 \\
\hline F10 & 19.66 & 52.635 & 32.975 \\
\hline F12 & 32.235 & 99.89 & 67.655 \\
\hline
\end{tabular}

a Taken from Ref [17] and $\Delta\left(\delta_{\exp }-\delta_{\text {the }}\right)$; difference between respective chemical shifts. 

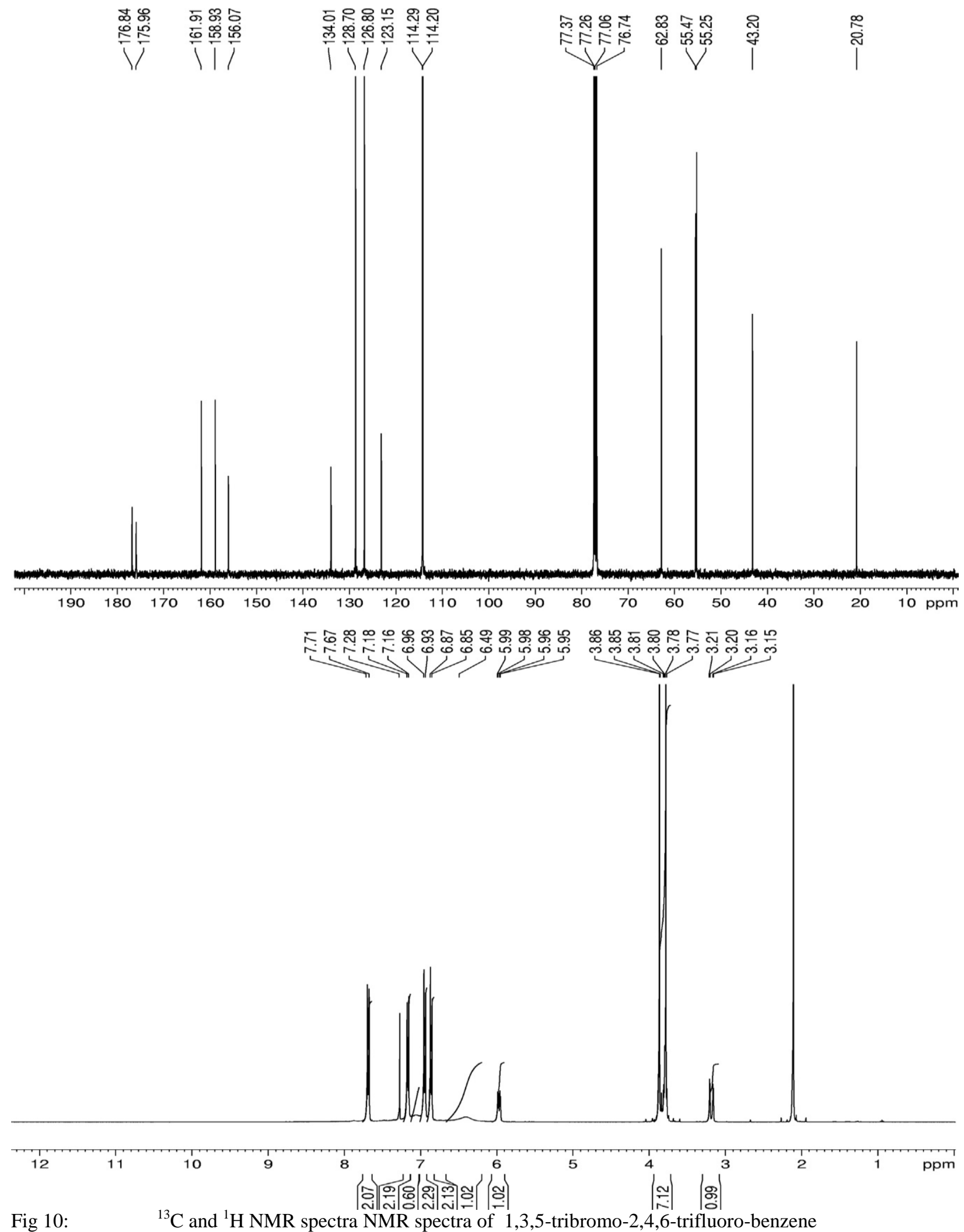

œ

\section{XI.TWO ROTOR PES SCAN STUDIES}

Conformational analysis was performed to determine the stable conformers, thereby sampling points on the potential energy surface (PES). In this PES scan process, the potential energy surface is built by varying the F12C6-C5-Br11 and $\mathrm{C} 3-\mathrm{C} 4-\mathrm{C} 5-\mathrm{C} 6$ dihedral angle from $0^{\circ}$ to $360^{\circ}$ in every $10^{\circ}$, while all of the other geometrical parameters have been simultaneously relaxed. The title molecule has several minima and maxima on the potential energy surface, and these minima and maxima are given in Fig. 11 The dark blue regions represent the more stable molecules with low total energy, while the dark red regions represent the unstable molecules with high total 
energies.

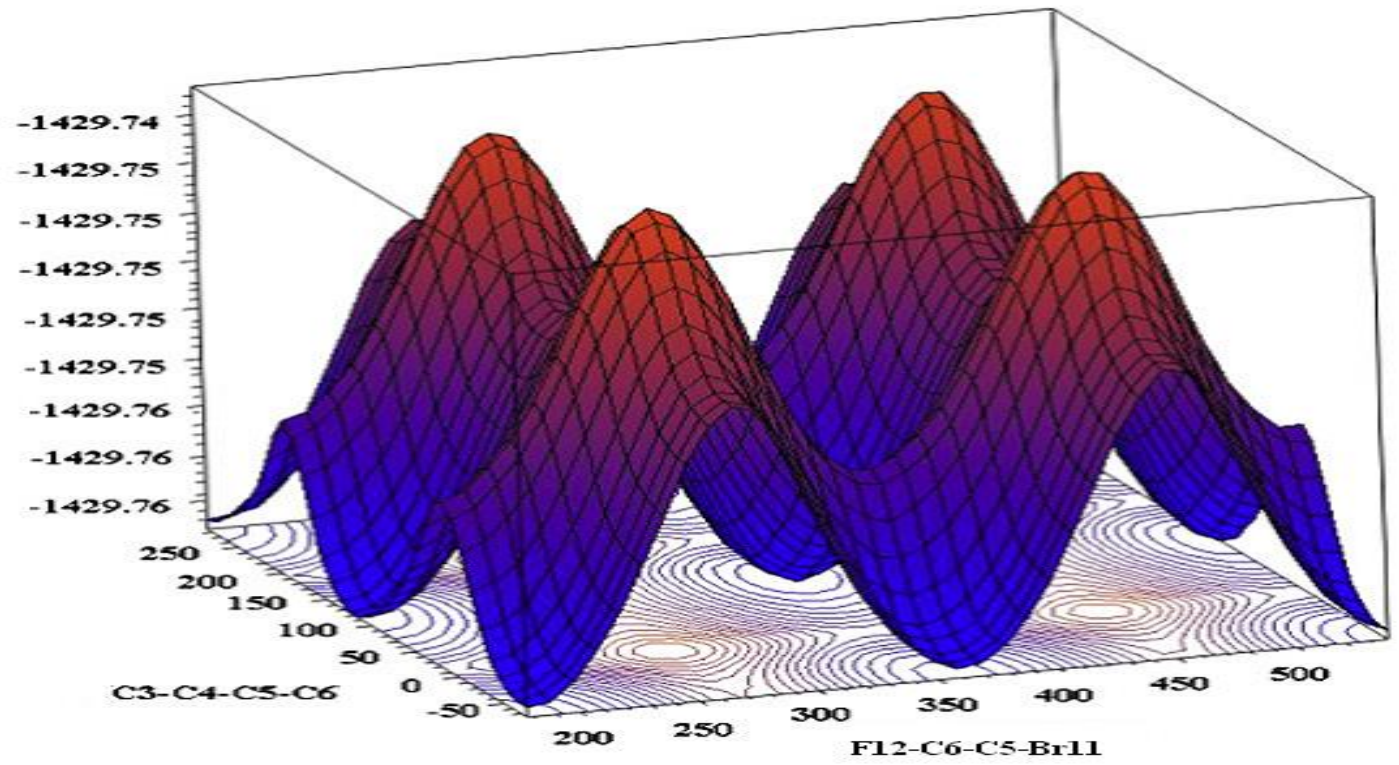

Fig 11.Two Rotor PES Scan of 1,3,5-tribromo-2,4,6-trifluoro-benzene.

\section{CONCLUSION}

The molecular structural parameters, thermodynamic properties and fundamental vibrational frequencies of the optimized geometry of 1,3,5-tribromo-2,4,6-trifluoro-benzene have been obtained from DFT calculations. The theoretical results are compared with the experimental vibrations. Although this types of calculations are useful to explain vibrational spectra of 1,3,5-tribromo-2,4,6-trifluoro-benzene, for DFT-B3LYP/6-311++G(d,p) level calculation methods. On the basis of agreement between the calculated and experimental results, assignments of all the fundamental vibrational modes of 1,3,5-tribromo-2,4,6-trifluoro-benzene have been made for the first time in this investigation. The electric field influence is noticed TED calculation regarding the normal modes of vibration provides a strong support for the frequency assignment. Therefore, the assignments proposed at higher level of theory with higher basis set with only reasonable deviations from the experimental values seem to be correct. NMR, NBO analysis have been performed in order to elucidate charge transfers or conjugative interaction, the intra-molecule rehybridization and delocalization of electron density within the molecule. The electric field influence is noticed in HOMO-LUMO gaps for 1,3,5-tribromo-2,4,6-trifluoro-benzene. The HOMO-LUMO gap extensively decreases from $0.0409 \mathrm{eV}$ to $0.1789 \mathrm{eV}$ for 1,3,5-tribromo-2,4,6-trifluoro-benzene, respectively as the electric field increases. Thus the present investigation is providing the complete vibrational assignments, structural information and electronic properties of the title compounds which may be useful to raise the knowledge on phenyl derivatives. MEP study shows that the electrophilic attack takes place at the Br position of 1,3,5-tribromo2,4,6-trifluoro-benzene.

\section{REFERENCES}

Olah,. Malhorta, Narang, Nitration Methods and Mechanisms, VCH, New York, 1989.

Becker,. Banik, Bioorg;Med. Chem. 8 (1998) 2877-2880.

Zollinger, Color Chemistry: Properties and Applications of Organic Dyes, 2nd

ed., John Wiley, New York, 1991.

Meyer, Kholar, Homburg, Explosives, 5th ed., John Wiley, New York,2002.

Ullmann's Encyclopedia of Industrial Chemistry, vol. A17, VCH, Weinheim,1991, p. 411.

Goddard, Pat. No. 4,001,272, January 4, 1977.

Palmer, Moyes, Spiers, Ridyard; J. Mol. Struct. 55 (1979) 243-263.

Muralidhar Rao, Ramana Rao; Raman Spectrosc. 20 (1989) 529-540.

Frisch M J,Trucks G W, Schlegal H B et at, Gaussian 09, Revision A 02, Gaussian, Inc, ～Wallingford CT, 2009.

Kuppusamy Sambathkumar, Nithiyanantham;J Mater Sci: Mater Electron DOI 10.1007/s 10854-017-6342-7

Kuppusamy Sambathkumar, Density Functional Theory Studies of Vibrational Spectra, Homo- Lumo, Nbo and Nlo Analysis of

Some Cyclic and Heterocyclic Compounds (Ph.D. thesis), Bharathidasan University, Tiruchirappalli, August 2014.

Kuppusamy Sambathkumar; Elixir Vib. Spec. 91 (2016) 38381-38391.

Kuppusamy Sambathkumar Spectrochim. Acta A 147 (2015) 51-66.

Cecily Mary Glory, Madivanane and Kuppusamy Sambathkumar Elixir Comp. Chem; 89 (2015) 36730-36741.

Kuppusamy Sambathkumar AlbertClaude and Settu ;Elixir Vib. Spec.91(2016) 38368-38380.

Balachandran, Rajeswari, Lalitha; Spectrochim. Acta A 124 (2014) 277-284.

http://riodbol.ibase.aist.go.jp/sbds/(National Institute of Advanced Industrial Science. 